\title{
Planejamento da rentabilidade no processo de conversão do café convencional para o orgânico: Um estudo de caso
}

\author{
Renato Alves Oliveira \\ Doutorado em Economia Aplicada pela Escola Superior de Agricultura Luiz de \\ Queiroz - ESALQ \\ Professor da Universidade Estadual de Ponta Grossa - UEPG \\ Praça Santo Andrade s/n. Centro. Ponta Grossa/PR \\ E-mail: natoliveiralves@hotmail.com
}

\section{RESUMO}

Esta pesquisa buscou verificar a viabilidade econômica em converter uma propriedade de café convencional, situada em Espírito Santo do Pinhal-São Paulo, para orgânico. Utilizou-se um modelo matemático linear para a simulação da produção do café em conversão. Constatou-se que o quarto ano do planejamento é considerado crítico, pois reduz drasticamente o lucro do produtor e verificou-se que a produção orgânica teve um resultado de lucro simulado maior do que o sistema convencional. Conclui-se que pode ser economicamente viável a adoção da produção orgânica na cultura do café, mas isso depende da diferença de preço entre os sistemas convencional e orgânico.

Palavras-chave: Agricultura Orgânica. Café. Planejamento da conversão.

\section{Planning profitability in the process conversion of conventional coffee for organic: A case study}

\section{ABSTRACT}

This research analyzes the economic feasibility of converting a conventional coffee estate, located in Espírito Santo do Pinhal, São Paulo, to organic. A linear mathematical model for simulation the production of coffee in conversion was used. It was found that the fourth year of planning is considered critical, it drastically reduces the producer's profit and it was found that organic production had a result greater than the conventional system simulated profit. The conclusion that can be economically feasible the adoption of organic production of coffee culture, but is dependent on the price difference between conventional and organic systems.

Keywords: Organic Agriculture, Coffee, planning the conversion. 


\section{INTRODUÇÃO}

Alguns cafeicultores estão adotando a Agricultura Orgânica na busca por um produto diferenciado, para agregação de valor, por aumento na lucratividade e pela aceitação dos consumidores, principalmente os do mercado externo.

Um dos procedimentos para que uma propriedade se torne orgânica é o processo de conversão ou transição. "Conversão é o nome dado ao processo de mudanças do manejo convencional para o orgânico, com enfoque nos aspectos educativos, biológicos e normativos" (MAIORANO, 2000, p.13).

Para analisar o processo de conversão foi realizada uma análise contábil para a produção orgânica de café no Sítio Terra Verde em Espírito Santo do Pinhal, no Estado de São Paulo. Com isso, será verificada a viabilidade econômica da produção agrícola, para identificar se a técnica orgânica, aplicada ao café, com seus benefícios e limitações, pode sustentar-se economicamente durante e após o processo de conversão, inclusive de maneira comparativa à técnica convencional ao longo de oito anos.

Na literatura não há trabalhos que tratam sobre o processo de conversão da propriedade sobre aspectos de rentabilidade ou contábil para observar pontos críticos no momento da mudança. Encontram-se apenas inúmeros trabalhos que realizam comparativos pontuais entre o convencional e o orgânico.

Para isso este trabalho pretende simular a possibilidade de o cafeicultor convencional produzir organicamente apresentando os riscos envolvidos durante o processo.

Esta pesquisa tem como objetivo verificar a viabilidade econômica da produção orgânica de café no Sítio Terra Verde em Espírito Santo do Pinhal, no Estado de São Paulo, sobre um cenário observando o lucro, o custo e a produção de café de maneira comparativa ao sistema convencional.

\section{ARCABOUÇO TEÓRICO}

Nesta seção serão apresentados os conceitos que regem a agricultura orgânica; a agricultura orgânica como uma mudança tecnológica ao sistema 
convencional; o cenário internacional e nacional; e um levantamento de estudos sobre a agricultura orgânica.

\subsection{Agricultura Orgânica - AO}

O sistema orgânico de produção agropecuária é considerado pela legislação brasileira de produtos orgânicos como todo aquele em que se adotam técnicas específicas, mediante a otimização do uso dos recursos naturais e socioeconômicos disponíveis e o respeito à integridade cultural das comunidades rurais. Tem por objetivo garantir a sustentabilidade econômica e ecológica, a maximização dos benefícios sociais, a minimização da dependência de energia não renovável, empregando, sempre que possível, métodos culturais, biológicos e mecânicos, em contraposição ao uso de materiais sintéticos, a eliminação do uso de organismos geneticamente modificados e radiações ionizantes, em qualquer fase do processo de produção, processamento, armazenamento, distribuição e comercialização, e a proteção do meio ambiente (Lei n. 10.831, de dezembro de 2003, BRASIL, 2003).

A Agricultura Orgânica é um sistema que sustenta a produção agrícola evitando ou excluindo em grande parte 0 uso dos fertilizantes e agrotóxicos sintéticos. Sempre que possível, recursos externos, tais como os químicos e combustíveis adquiridos por via comercial, são substituídos por recursos encontrados na unidade de produção agrícola ou próximo a ela. Esses recursos internos incluem energia solar ou eólica, controles biológicos de pragas, o nitrogênio fixado biologicamente e outros nutrientes liberados da matéria orgânica ou das reservas do solo. As opções específicas nas quais a Agricultura Orgânica encontrase baseada, tanto quanto possível, incluem rotações de cultura, resíduos de lavouras, esterco animal, uso de leguminosas e adubos verdes, resíduos externos à unidade produtiva, cultivo mecânico e rochas moídas que contenham minerais etc. (ALTIERE, 2004).

Penteado (2009) definiu a AO como um sistema de produção agrícola baseado em princípios ecológicos, em que o trabalho na terra está dentro de princípios de preservação do meio ambiente, que abrangem o manejo adequado dos recursos naturais e do solo, a nutrição vegetal, a proteção das plantas e a valorização dos recursos humanos. 
Segundo o Ministério da Agricultura, Pecuária e Abastecimento-MAPA, a AO busca criar ecossistemas mais equilibrados, preservar a biodiversidade, os ciclos e as atividades biológicas do solo (BRASIL, 2014).

As crescentes preocupações tanto com a preservação do meio ambiente quanto com os danos causados à saúde e ao bem-estar do homem, devido à utilização de insumos químicos sintéticos na produção de alimentos, têm impulsionado o crescimento do mercado de produtos orgânicos (BARBOSA; SOUZA, 2012).

Dessa maneira, a Agricultura Orgânica é um meio pelo qual os produtores e consumidores adquirem um produto com ausência de substâncias tóxicas, preservando o solo, a água, os vegetais, os animais e o ar, indo ao encontro de uma vida mais saudável e duradoura.

\subsection{Mudança tecnológica}

Pode-se definir mudança tecnológica como um processo por meio do qual um indivíduo ou grupo de indivíduos passa do primeiro contato com uma inovação até o uso completo e contínuo dela. Uma inovação é uma ideia ou prática percebidas como novas por um indivíduo, embora tal ideia ou prática possam não ser objetivamente novas (MESQUITA, 1996, p. 162).

De acordo com Jaffe, Newell e Stavins (2002), seguindo as ideias de Schumpeter, a mudança tecnológica passa por três fases: invenção, inovação e difusão. A invenção é uma criação de um processo, técnica ou produto inédito. $A$ inovação é a primeira comercialização de um produto ou processo no mercado. A difusão é uma forma de tornar disponível a adoção da inovação para as empresas ou indivíduos.

Barbieri (1990, in SACHUCK; TAKAHASHI; AUGUSTO, 2008) afirma que a inovação tecnológica corresponde a toda mudança numa dada tecnologia. É pela inovação que se introduz efetivamente um novo produto ou processo ou se aperfeiçoam os já existentes.

As inovações tecnológicas levam, por exemplo, ao aumento da oferta agrícola no longo prazo (MENDES, 1989). 
Na visão de Schumpeter, segundo Moricochi e Gonçalves (1994), "inovação" significa "fazer as coisas diferentemente no reino da vida econômica". A introdução de um novo bem não familiar aos consumidores, o estabelecimento de um novo método de produção, a abertura de um novo mercado, a descoberta de uma nova fonte de matéria-prima e a reorganização de uma indústria são exemplos de inovações.

A inovação é fortemente influenciada pelas incertezas que cercam a adoção de novas (ou velhas) tecnologias. O risco é uma variável crucial para a tomada de decisão sobre a introdução de uma técnica, mesmo quando seus resultados potenciais já são amplamente conhecidos (BUAINAIN et al., 2007).

Segundo Rogers (1995, in NUTLEY, 2002), a difusão é o processo pelo qual uma inovação é comunicada ao longo do tempo mediante certos canais, entre os membros de um sistema social.

A ideia do modelo de difusão desenvolvida por Hayami e Ruttan, na visão de Mesquita (1998), proporcionou a difusão de melhores práticas na exploração agropecuária nas décadas de 1930 e 1950 nas regiões agrícolas mais avançadas. Para a ideia difusionista, o importante não é propriamente a transformação da agricultura convencional numa atividade moderna e dinâmica, mas sim, compatibilizar a taxa de crescimento da produção e da produtividade agrícola com o progresso dos demais setores da economia.

Ainda conforme o autor, a mudança tecnológica não depende, necessariamente, da constante geração de novos fatores de produção dentro de uma área geométrica delimitada e num certo horizonte temporal. Basta que tais fatores sejam difundidos entre todos os produtores para que o nível tecnológico geral seja elevado, implicando ganhos globais de produção e produtividade.

A difusão de técnicas por meio do processo tecnológico, além de vantagens econômicas, depende de vários fatores para alcançar um maior número de agricultores, como, por exemplo: disponibilidade de recursos materiais e de conhecimentos técnicos, suprimento adequado de insumos modernos, facilidade de crédito, habilidade gerencial dos empresários agrícolas etc (PAIVA, 1975).

Mudanças tecnológicas estão intensamente presentes nas agroindústrias, de modo a alocar os recursos disponíveis de maneira eficiente. Por exemplo, a 
tecnologia agrícola da Revolução Verde promoveu o aumento da produção de alimentos com uso de insumos industriais, da mecanização, de sementes geneticamente melhoradas etc. Todavia, dependendo do tipo de transformação tecnológica adotada, maior atenção deverá ser dada aos possíveis impactos ecológicos, socioeconômicos e na saúde.

Conforme Mesquita (1998) pode-se admitir que uma mudança tecnológica com a finalidade de racionalizar o uso de recursos naturais, principalmente do solo e da água, poderia melhorar de forma sensível a produtividade agrícola, ou seja, o modelo de conservação seria altamente benéfico.

O sistema da Agricultura Orgânica pode ser representado como uma mudança tecnológica diante do sistema convencional, pois com a adoção das técnicas orgânicas de produção os produtores podem aumentar a qualidade do produto; promover sistemas adequados, tanto na cadeia produtiva quanto nos canais de comercialização de produtos orgânicos; melhorar as condições de saúde dos indivíduos e do ecossistema; melhorar a qualidade ambiental e racionalizar a utilização dos recursos naturais, de modo a manter o equilíbrio ecológico para as futuras gerações.

A partir dos benefícios dessa tecnologia, a pesquisa busca incentivar produtores convencionais de café a adotarem a Agricultura Orgânica mostrando o planejamento contábil e o risco envolvido durante o processo de conversão.

\subsection{Cenário da Agricultura Orgânica Internacional e Nacional}

O cenário internacional apresentado a seguir foi delineado com base nas informações da FIBL e IFOAM (2011). O cenário nacional foi obtido com base no último Censo Agropecuário em 2006 a partir do IBGE (2006).

\subsubsection{Agricultura Orgânica Internacional}

A Agricultura Orgânica vem se desenvolvendo ao longo do tempo em todo o mundo. A área cultivada organicamente passou dos 11 milhões para 37,2 milhões de ha entre 1999 e 2009, ou seja, em 11 anos houve um aumento em torno de $238 \%$. Houve crescimento anual, em média, de $14,24 \%$ em área orgânica. 
Em relação à distribuição por área e o número de produtores orgânicos em 2009, o continente que apresenta maior área é a Oceania, com 12,1 milhões de ha, caracterizada principalmente por áreas de pastagem. No entanto, detém o menor número de produtores, em torno de oito mil. Em seguida vem a Europa, com 9,2 milhões de ha e 257 mil produtores. A América Latina apresenta a terceira posição em área (8,5 milhões de ha) e o quarto lugar em número de produtores (283 mil). Os continentes asiático, norte-americano e africano apresentam os seguintes valores de área (em milhões de hectares) e de número de produtores (em mil): 3,5 e 731; 2,6 e 17; 1 e 511, respectivamente.

Em relação aos dez países que registraram maiores áreas com Agricultura Orgânica em 2009, destaca-se a Austrália, com 12 milhões de hectares, tendo como principais produtos: carne, derivados de leite, cereais (trigo, centeio e aveia), grãos (soja e milho) e frutas (laranja e uva). Na segunda posição está a Argentina, com 4,4 milhões de hectares, tendo como produtos de maior importância cereais, oleaginosas, frutas, lã, carne bovina e carne ovina. Os Estados Unidos, China e Brasil ocupam a terceira (1,95 ha), quarta (1,85 ha) e quinta (1,77 ha) posições em área orgânica, respectivamente. Da sexta à décima posição estão a Espanha $(1,33$ milhões de ha), a Índia (1,18 milhões de ha), a Itália (1,11 milhões de ha), Alemanha (0,95 milhões de ha) e o Uruguai (0,93 milhões de ha).

\subsubsection{Agricultura Orgânica Nacional}

Do total da amostra de estabelecimentos agropecuários, 98,28\% (5.084.992) não fazem uso da Agricultura Orgânica e apenas 1,75\% (90.497) utilizam a técnica, do qual apenas $5,64 \%$ (5.106) são certificados por entidade credenciada, enquanto 94,36\% (85.391) não são certificados.

No uso da Agricultura Orgânica nos estabelecimentos por região, nota-se que a Região Nordeste é a que possui maior número de estabelecimentos que produzem organicamente (42.236). Porém o número de estabelecimentos com certificado orgânico é maior nas regiões Sul (1.924) e Sudeste (1.366).

Sendo certificada ou não, o Brasil possui uma área média, em produção orgânica, de 4.424.955 hectares. É interessante perceber que, segundo os dados divulgados pela FIBL e IFOAM, o Brasil se encontra na quinta posição em termos de 
área, como verificado anteriormente. No entanto, de acordo com o Censo Nacional, - Brasil deveria estar somente atrás da Austrália, igualando-se à Argentina, passando assim para a segunda posição no ranking.

A área certificada é de 391.827 ha, sendo 31\% de participação nordestina, e a área não certificada, de 4.033.128,15 ha, tendo também o Nordeste com maior participação (34\%).

Sobre a área orgânica total estimada, em mil hectares, por região, observa-se que o Nordeste tem maior área de produção orgânica, com 1,5 milhões de ha, e a Região Sul apresenta a menor área orgânica, com 583 mil ha. As outras regiões (Sudeste, Centro-Oeste e Norte) detêm uma área de 1,008 milhões, 732 milhões e 598 milhões de hectares, respectivamente.

São Paulo, Paraná e Santa Catarina são os três maiores estados com estabelecimentos orgânicos certificados, com 13,38\%, 12,08\% e 10,98\%, respectivamente, em relação ao total de estabelecimentos. O uso sem certificado é de $97,02 \%$ e $95,03 \%$, respectivamente, para a Bahia e Minas Gerais, os quais apresentam maior número de estabelecimentos orgânicos de produção. Juntos estes cinco estados correspondem a, aproximadamente, $80 \%$ do total de estabelecimentos com uso da Agricultura Orgânica.

Os estabelecimentos de produtores orgânicos dedicavam-se principalmente à pecuária e à criação de outros animais (42,01\%), às lavouras temporárias (33,34\%) e às lavouras permanentes (10,56\%). Quanto à horticultura/floricultura, 9,83\%; a produção florestal soma 3,63\% e aos grupos restantes corresponde menos que $1 \%$.

Com base nas atividades orgânicas, em estabelecimentos, Minas Gerais se especializou mais em pecuária (7.055), lavoura permanente (1.257) e horticultura e floricultura (1.208); a Bahia em pecuária (5.697) e nas lavouras temporária (5.385) e permanente (2.450); o Rio Grande do Sul em pecuária (4.338) e horticultura e floricultura (1.089); o Paraná (3.188) e Pernambuco (1.944) em pecuária; o Ceará em lavoura temporária (2.480) e pecuária (1.670); Santa Catarina em pecuária (1.535) e São Paulo em pecuária (1.372) e horticultura e floricultura (962).

Destaca-se a atividade pecuária como a de maior área em sistema orgânico, certificado ou não certificado, com aproximadamente 2,5 milhões de hectares; em segundo lugar vem a lavoura temporária com quase um milhão de ha; em terceiro, a 
lavoura permanente (431.812 ha); por último, a horticultura e floricultura (173.857 ha). As maiores áreas por atividade e respectivos estados são: pecuária (Minas Gerais, Bahia, Mato Grosso e Rio Grande do Sul), lavoura temporária (Minas Gerais, Bahia, Maranhão e Rio grande do Sul), lavoura permanente (Bahia, Minas Gerais, Pará e Espírito Santo) e horticultura e floricultura (Minas Gerais, Bahia, São Paulo e Rio Grande do Sul).

Quanto à participação de estabelecimentos por condição do produtor, $77,29 \%$ correspondem à condição de proprietário; 8,61\% de ocupante; assentado, arrendatário e parceiro somam 10,56\%; e produtor sem área 3,53\%. Essa informação sugere que os donos das terras estão investindo bastante na Agricultura Orgânica.

\subsection{Estudos realizados sobre a temática}

Turco, Oliveira e Bueno (2010) estimaram o custo operacional de implantação em sistema convencional e orgânico da cultura do café em São Paulo e Minas Gerais, em um hectare, espaçamento de 3,7 x 0,7 m. A partir dos dados, observa-se que os custos com mão de obra foram entre $30 \%$ e $34 \%$ maiores no sistema orgânico que no convencional. Também se verifica que o custo operacional total para implantação em sistema orgânico foi $11 \%$ menor que no convencional, e em sistema orgânico de montanha foi $15 \%$ menor.

Silva Junior et al. (2012) realizaram um comparativo entre o sistema convencional e o orgânico do morango em Rancho Queimado (SC). Observaram que orgânico tem maiores custos operacionais, proporcionalmente maior produtividade e também pode apresentar maior receita.

Ao analisar qual tipo de sistema de cultivo de café arábica - convencional ou orgânico - fornece maior sustentabilidade socioeconômica aos cafeicultores familiares no Estado do Espírito Santo, Siqueira, Souza e Ponciano (2011) verificaram que ambos os sistemas foram viáveis, embora tenha se observado indicadores pouco melhores para o cultivo orgânico. Contudo, para os cafeicultores, há maior dependência do diferencial de preço (prêmio) entre o café orgânico e o convencional para se compensar a menor produtividade do orgânico. 
Siqueira e Souza (2012), ao analisarem o custo e a rentabilidade de sistemas convencionais de café com três níveis de produtividade e o sistema orgânico em Caparaó-ES, identificaram que o preço recebido pelo café foi a variável que exerceu a maior influência na rentabilidade dos produtores familiares e o sistema orgânico foi muito dependente do prêmio de mercado para se tornar viável, pois apresentou a menor produtividade.

Ao verificarem, no Estado do Piauí, o impacto dos sistemas de cultivo convencional e orgânico de frutas sobre indicadores biológicos de qualidade do solo, Sampaio, Araújo e Santos (2008) observaram que a adoção do sistema orgânico aumentou a atividade microbiana e o conteúdo de carbono orgânico do solo, mostrando benefícios para esse sistema agrícola em relação ao convencional.

Ao diagnosticarem aspectos técnico-ambientais da produção orgânica na região citrícola do Vale do Rio Caí, no Rio Grande do Sul, Panzenhagen et al. (2008) concluíram que a produção orgânica de alimentos resultou em benefícios para as populações locais, tal como a redução da contaminação ambiental, contribuindo na recuperação e melhoria da qualidade dos recursos naturais e na colheita de produtos sem contaminações por agroquímicos, o que permite que o agricultor produza e ofereça ao mercado consumidor produtos de melhor qualidade.

Analisando a produção e os mercados orgânicos de laranja e suco de laranja processados no Brasil, Turra e Ghisi (2004) concluíram que grande parte dos produtores considerou o custo de produção de citros orgânico mais elevado que na produção convencional. No entanto, os citricultores afirmaram que houve regularidade na produtividade e consideraram o preço de comercialização viável, podendo receber das indústrias uma remuneração até 30\% maior que a paga aos produtores convencionais.

Martins et al. (2006) desenvolveram um estudo da viabilidade de conversão de áreas cultivadas de maneira convencional para um método de cultivo orgânico para a produção de uvas. Tiveram como resultado que a Agricultura Orgânica na produção vitivinícola é viável tanto econômica quanto socialmente, por ser um fator de agregação econômico, humano e ambiental. Afirmaram, ainda, que sendo o custo de produção inferior ao custo da agricultura convencional, devido ao menor uso de 
insumos isentos de agrotóxicos e por não agredir o meio ambiente, torna-se uma fonte de emprego e renda para a agricultura familiar.

Motta et al. (2008), analisando economicamente a produção de maracujáamarelo em sistemas orgânico e convencional, verificaram maior viabilidade econômica para o cultivo orgânico, apresentando menores gastos com insumos e produtividade superior ao sistema convencional.

\section{METODOLOGIA}

Nesta seção serão apresentados o material, que abrange a coleta de dados e a descrição do estudo de caso, e o método utilizado para realização do planejamento do processo de conversão do café convencional para o orgânico.

\subsection{Material}

Um questionário foi aplicado sobre as safras 2010/2011 e 2011/2012 para a obtenção de informações técnicas-agronômicas da unidade produtiva de café convencional, Sítio Terra Verde, em Espírito Santo do Pinhal, Estado de São Paulo.

O questionário foi elaborado por perguntas abertas ao cafeicultor coletando informações sobre os custos de produção, custos administrativos, custos de secagem e beneficiamento do café, preço de venda da saca, produtividade dos talhões, o tamanho da área, a variedade de café, bem como sobre a bienalidade para identificar a safra de alta e baixa produção.

A propriedade escolhida foi aleatória, mas foram levados em consideração: seu porte (médio produtor), índice pluviométrico da região (chuva média anual entre 1.500 e $1.900 \mathrm{~mm}$ ), variedade de café, tipo de solo (latossolo areno-argiloso) e a disponibilidade de o cafeicultor fornecer os dados. O método aplicado pode ser utilizado para qualquer propriedade de café, mas a resposta do modelo pode apresentar resultados diferentes, pois depende das limitações particulares de cada uma.

Para as safras2010/2011 e 2011/2012, respectivamente, os custos de secagem e beneficiamento do Sítio Terra Verde perfazem um total de $R \$ 864,06 /$ ha e $R \$ 703,55 /$ ha, os custos de administração foram de $R \$ 756,50 /$ ha e $R \$ 851,06 /$ ha, 
correspondendo a custos adicionais de $R \$ 68.549,74$ e $R \$ 65.760,17$ para toda área.

Considerando a alta nos preços do café, em novos patamares, a partir de 2011, a simulação do plano de manejo para a conversão do café adotará a fixação do preço $(R \$ 499,38)$ da saca da safra $2011 / 2012$ e fixará o preço ( $R \$ 382,90)$ da saca da safra 2010/2011 com base na tendência dos preços para o ano 2012. A simulação referente à safra 2010/2011 apresentará receita de $R \$ 420.872,20$ e lucro bruto de $R \$ 138.668,85$ para produzir $1.099,17$ sacas de café. Para produzir 705,69 sacas de café houve um gasto total de $R \$ 263.544,02$; a receita bruta do cafeicultor foi de $R \$ 352.407,47$, o que resultou num lucro bruto de $R \$ 88.863,45$ na safra $2011 / 2012$.

\subsection{Planejamento de conversão para o café orgânico no Sítio Terra Verde}

É possível realizar a conversão parcial na unidade produtiva, sendo prevista no plano de manejo, a conversão total de toda a unidade de produção, do manejo convencional para o orgânico, de acordo com o Regulamento Técnico para os Sistemas Orgânicos de Produção Animal e Vegetal (BRASIL, 2008).

A simulação do processo de conversão do café, nesta pesquisa, foi estabelecida por um período de 24 meses para que a propriedade seja considerada como orgânica. A área será dividida em talhões para se identificar o tipo de manejo adotado, pois esta divisão facilitará a reestruturação da propriedade e o planejamento das ações.

A pesquisa adotará o plano de manejo da conversão parcial do café, passando por três fases de manejo: substituição parcial de insumos, em conversão e orgânico.

Ricci, Araújo e Castro (2002) não aconselham a conversão completa no primeiro ano, isto é, substituir todo o fertilizante químico pelo orgânico, pois a conversão imediata pode submeter a planta a um estresse nutricional, predispondoa ao ataque severo de pragas e doenças. Nesse sentido, em todos os talhões serão feitas substituições parciais dos insumos convencionais pelos orgânicos com aplicações na proporção 1 (C) convencional : 2 (O) orgânicos no 1ํano; para o $2^{\circ}$ ano em diante serão apenas insumos orgânicos, iniciando-se assim a contagem 
para o processo de conversão. A área está proporcionalmente dividida entre os quatro talhões.

A pesquisa adotará o plano de manejo da conversão parcial do café (Tabela 1), passando por três fases de manejo: substituição parcial de insumos, em conversão e orgânico. Durante a fase de conversão deve-se aplicar o manejo orgânico de produção; no entanto, o café adquirido não estará classificado como produto orgânico para a comercialização, permanecendo o preço do café convencional.

Tabela 1 - Plano de Manejo para o processo de conversão parcial do café convencional em café orgânico no Sítio Terra Verde

\begin{tabular}{|c|c|c|c|c|c|c|}
\hline PERÍODO & SAFRAS & $\begin{array}{c}\text { PRODUÇÃO } \\
\text { (Bienal) }\end{array}$ & TALHÃO & ÁREA & MANEJO & APLICAÇÃO \\
\hline \multirow{2}{*}{$\begin{array}{l}\text { ANO } \\
\text { BASE }\end{array}$} & $2010 / 2011$ & Alta & $1,2,3$ e 4 & $100 \%$ & Convencional & $3 C$ \\
\hline & $2011 / 2012$ & Baixa & $1,2,3$ e 4 & $100 \%$ & Convencional & $3 C$ \\
\hline \multirow{2}{*}{ 1 ANO } & \multirow{2}{*}{$2012 / 2013$} & \multirow{2}{*}{ Alta } & 1 & $7,6 \%$ & Substituição & $1 \mathrm{C} 2 \mathrm{O}$ \\
\hline & & & 2,3 e 4 & $92,4 \%$ & Convencional & $3 C$ \\
\hline \multirow{3}{*}{ 2\% ANO } & \multirow{3}{*}{$2013 / 2014$} & \multirow{3}{*}{ Baixa } & 1 & $7,6 \%$ & Em Conversão & 30 \\
\hline & & & 2 & $22,9 \%$ & Substituição & $1 \mathrm{C} 2 \mathrm{O}$ \\
\hline & & & 3 e 4 & $69,5 \%$ & Convencional & $3 C$ \\
\hline \multirow{4}{*}{ 3 ANO } & \multirow{4}{*}{$2014 / 2015$} & \multirow{4}{*}{ Alta } & 1 & $7,6 \%$ & Em Conversão & 30 \\
\hline & & & 2 & $22,9 \%$ & Em Conversão & 30 \\
\hline & & & 3 & $29,1 \%$ & Substituição & $1 \mathrm{C} 2 \mathrm{O}$ \\
\hline & & & 4 & $40,4 \%$ & Convencional & $3 C$ \\
\hline \multirow{4}{*}{ 4 ANO } & \multirow{4}{*}{$2015 / 2016$} & \multirow{4}{*}{ Baixa } & 1 & $7,6 \%$ & Orgânico & Certificado \\
\hline & & & 2 & $22,9 \%$ & Em Conversão & 30 \\
\hline & & & 3 & $29,1 \%$ & Em Conversão & 30 \\
\hline & & & 4 & $40,4 \%$ & Substituição & $1 \mathrm{C} 2 \mathrm{O}$ \\
\hline \multirow{3}{*}{ 5\% ANO } & \multirow{3}{*}{$2016 / 2017$} & \multirow{3}{*}{ Alta } & $1 \mathrm{e} 2$ & $30,5 \%$ & Orgânico & Certificado \\
\hline & & & 3 & $29,1 \%$ & Em Conversão & 30 \\
\hline & & & 4 & $40,4 \%$ & Em Conversão & 30 \\
\hline \multirow{2}{*}{ 6 ANO } & \multirow{2}{*}{$2017 / 2018$} & \multirow{2}{*}{ Baixa } & 1,2 e 3 & $59,6 \%$ & Orgânico & Certificado \\
\hline & & & 4 & $40,4 \%$ & Em Conversão & 30 \\
\hline $7^{\circ}$ ANO & $2018 / 2019$ & Alta & $1,2,3$ e 4 & $100 \%$ & Orgânico & Certificado \\
\hline 8 ANO & $2019 / 2020$ & Baixa & $1,2,3$ e 4 & $100 \%$ & Orgânico & Certificado \\
\hline
\end{tabular}

Fonte: Delineamento utilizado no estudo

Este estudo irá assim comparar os dois sistemas: o convencional e o orgânico (em cenários). Para que seja possível tal comparação, será considerado um caso em que o produtor do Sítio Terra Verde não adote a conversão do café para o orgânico ao longo do período de oito anos. As variáveis das safras 2010/2011 e 
2011/2012 permanecerão constantes ao longo do período em sistema convencional, obedecendo à bienalidade do café.

\subsection{Caracterização dos parâmetros incorporados ao plano de manejo}

Os fatores (em percentual) incorporados ao modelo desta pesquisa correspondentes ao preço do café orgânico, ao custo de produção e à produtividade, foram obtidos por meio das referências citadas a seguir.

\subsubsection{Fator Preço}

O café arábica produzido organicamente, em geral, obtém preço $20 \%$ a $50 \%$ acima do preço da saca cultivada convencionalmente (SAES; SOUZA; OTANI, 2001).

Diante disso, foi adotado o fator $30 \%$ sobre o preço da saca de café convencional quanto o café estiver em manejo orgânico.

\subsubsection{Fator Produtividade}

Assis e Romeiro (2004), analisando a conversão para a Agricultura Orgânica quanto à produção de café, numa amostra de 20 cafeicultores, tanto familiares quanto empresariais, verificaram que no início do processo de transição houve perda de produtividade, a qual variou de $10 \%$ a $80 \%$, entre 15 entrevistados; para os outros produtores a mudança não apresentou redução da produtividade. A recuperação da produtividade mostrou muitas variações: para sete cafeicultores retornou ao nível inicial entre 1 e 6 anos; para seis produtores houve recuperação parcial de $10 \%$ a 50\%, após 2 a 5 anos; para dois agricultores, não houve recuperação após 4 anos.

Na Agricultura Orgânica, segundo Santos e Santos (2008) apud Alencar et al. (2009), há limitações quanto à redução de produtividade, que é em média $30 \%$ menor.

Dessa forma, foram estabelecidos fatores de $10 \%, 20 \%$ e $30 \%$ para redução da produtividade durante o processo de conversão. 


\subsubsection{Fator Custo}

Segundo pesquisa do PENSA (2009), o custo adicional de se produzir café especial (qualidade orgânico) em relação ao café convencional, entre os cafeicultores entrevistados, foi de 1 a $10 \%$ para $29 \%$ dos produtores; 11 a $20 \%$ para $50 \%$ dos produtores; 21 a $30 \%$ para $16 \%$ dos produtores e maior que $31 \%$ para $4 \%$ dos produtores.

Desse modo, adotaram-se fatores de 10\%, 20\% e 30\% para aumentos de custos de produção ao processo de conversão.

\subsection{Método}

O modelo adotado nesta pesquisa se refere a uma função linear, em que os coeficientes relacionados ao fator custo, preço e produtividade foram alterados de acordo como o plano de manejo da pesquisa, correspondente à respectiva produtividade de cada talhão.

Segundo Bradley (2011), a modelagem matemática pode ser classificada como abstrata (dinâmica), sendo o modelo adotado nesta pesquisa de caráter determinístico.

No entanto, é importante frisar que esta modelagem não é de programação linear, pois não se pretende alcançar um ponto ótimo, mas fazer uma simulação contábil não otimizada e verificar sua viabilidade econômica com base no planejamento da conversão para o orgânico. A formulação do modelo detalhado segue abaixo.

\subsubsection{Construção matemática}

O modelo matemático linear é composto por funções lineares para a obtenção do lucro, custo total e receita; cinco equações (custo de colheita, custo de adubação, custo de defensivos, produção e produtividade) e quatro variáveis de decisão (produtividades dos quatro talhões) do qual seus valores não podem ser maiores do que os informados na Tabela 2. A aplicação do método foi realizada para cada ano simulado, conforme resultados apresentados no Anexo 1. O software Excel foi utilizado para gerar os resultados. 


\section{i. Lucro igual a:}

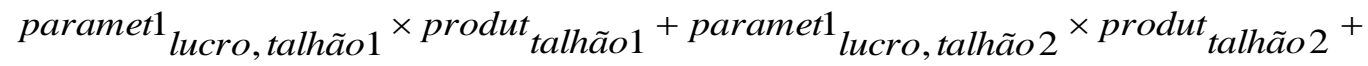

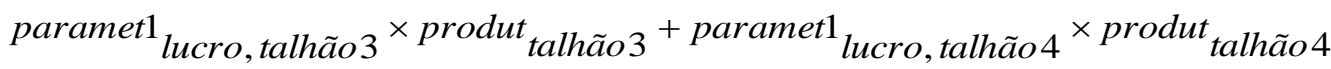

\section{ii. Custo total igual a:}

$$
\begin{aligned}
& \text { paramet } 2_{\text {custo, talhão } 1} \times \text { produt }_{\text {talhão } 1}{ }^{+ \text {paramet } 2}{ }_{\text {custo, } \text { talhão } 2} \times \text { produt }_{\text {talhão } 2}{ }^{+} \\
& \text {paramet } 2_{\text {custo, talhão } 3} \times \text { produt }_{\text {talhão } 3}{ }^{+ \text {paramet } 2}{ }_{\text {custo, talhão } 4} \times \text { produt }_{\text {talhão } 4}
\end{aligned}
$$

iii. Receita igual a:

$$
\begin{aligned}
& { }^{\text {paramet } 3}{ }_{\text {receita, talhão } 1} \times \text { produt }_{\text {talhão } 1}{ }^{+ \text {paramet } 3}{ }_{\text {receita, talhão } 2} \times \text { produt }_{\text {talhão } 2}{ }^{+} \\
& \text {paramet }{ }_{\text {receita, talhão } 3} \times \text { produt }_{\text {talhão } 3}{ }^{+ \text {paramet } 3}{ }_{\text {receita }, \text { talhão } 4} \times \text { produt }_{\text {talhão } 4}
\end{aligned}
$$

\section{iv. Custo de Adubação igual a:}

$$
\begin{aligned}
& \text { paramet } 4_{C A, \text { talhão } 1} \times \text { produt }_{\text {talhão } 1}{ }^{+ \text {paramet } 4}{ }_{C A, \text { talhão } 2} \times \text { produt }_{\text {talhão } 2}{ }^{+} \\
& { }_{\text {paramet } 4}{ }_{C A, \text { talhão } 3} \times \text { produt }_{\text {talhão } 3}+\text { paramet } 4_{C A \text {, talhão } 4} \times \text { produt }_{\text {talhão } 4}
\end{aligned}
$$

\section{v. Custo de Defensivo igual a:}

$$
\begin{aligned}
& \text { paramet }{ }_{C D, \text { talhão } 1} \times \text { produt }_{\text {talhão } 1}+\text { paramet } 5{ }_{C D, \text { talhão } 2} \times \text { produt }_{\text {talhão } 2}+ \\
& \text { paramet } 5 \text { CD, talhão } 3 \times \text { produt }{ }_{\text {talhão } 3}+\text { paramet } 5 \text { CD, talhão } 4 \times \text { produt }{ }_{\text {talhão } 4}
\end{aligned}
$$

\section{vi. Custo de Colheita igual a:}

$$
\begin{aligned}
& { }_{\text {paramet } 6}{ }_{C C, \text { talhão } 1} \times \text { produt }_{\text {talhão } 1}+\text { paramet } 6{ }_{C C \text {, talhão } 2} \times \text { produt }{ }_{\text {talhão } 2}+ \\
& \text { paramet }{ }_{C C} \text {, talhão } 3 \times \text { produt }_{\text {talhão } 3}{ }^{+ \text {paramet } 6}{ }_{C C \text {, talhão } 4} \times \text { produt } \text { talhão } 4
\end{aligned}
$$

\section{vii. Produção igual a:}

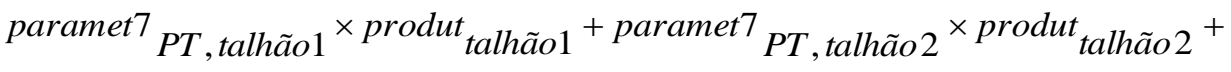

$$
\begin{aligned}
& { }_{\text {paramet } 7}^{P T, \text { talhão } 3}{ }^{\times \text {produt }} \text { talhão3 }{ }^{+ \text {paramet }{ }_{P T} \text {, talhão } 4} \times \text { produt }_{\text {talhão } 4}
\end{aligned}
$$


viii. Talhão 1) produt talhão1 $\leq$ produtmáx talhão1

ix. Talhão 2) produt talhão $2 \leq$ produtmáx $_{\text {talhão } 2}$

x. Talhão 3) produt $_{\text {talhão } 3} \leq$ produtmáx ${ }_{\text {talhão3 }}$

xi. Talhão 4) produt $_{\text {talhão } 4} \leq$ produtmáx $_{\text {talhão } 4}$

A cada parâmetro foi atribuído o valor da variável unitária (lucro, custo total, custo de adubação, custo de defensivo, custo de colheita) ao seu respectivo talhão vezes a área do talhão e os fatores atribuídos do planejamento de conversão, sendo lucro unitário = Paramet $1_{\text {lucro, talhão }}$; custo total unitário=Paramet $2_{\text {custo,talhão }}$; receita unitária = Paramet $3_{\text {receita,talhão } ; \text { custo de adubação }}$ unitário Paramet ${ }^{4} C A$,talhão ; ; de colheita unitário $=$ Paramet ${ }_{C C}$, talhão $;$ produção unitária $=$ Paramet ${ }^{7} P T$, talhão ; produtividade $=$ produt $_{\text {talhão }}$.

\subsection{Cenário do café em conversão para o orgânico}

Foi analisado um cenário para tratar o problema para a obtenção do lucro no processo de conversão.

Nesse cenário ocorreram reduções na produtividade de $10 \%$ em manejo em substituição, de $20 \%$ ( $1^{\circ}$ ano) e de $30 \%$ ( $2^{\circ}$ ano) em manejo em conversão; em manejo orgânico não houve aplicação de fator redutor. Houve aumento nos custos de adubação, defensivos e colheita, de $10 \%$ na fase de substituição, $20 \%$ no $1^{\circ}$ ano de conversão, $30 \%$ no $2^{\circ}$ ano de conversão e 30\% em manejo orgânico. Após o respectivo talhão ter passado pelo manejo em conversão, o preço do café orgânico foi $30 \%$ maior que o preço do café convencional. 
Foram adicionados aos resultados os custos de secagem, beneficiamento e administrativo para verificar a viabilidade econômica do planejamento de conversão, mediante a obtenção do custo geral e do lucro geral.

A simulação acompanhou a bienalidade da produção do café em que o ano de "alta" será representado pela safra 2010/2011 e o ano de "baixa" será representado pela safra 2011/2012. O plano de manejo será iniciado pelo ano de alta produção (safra 2012/2013) e terminará no ano de baixa produção (safra 2019/2020). A Tabela 2 apresenta, de forma sumarizada, o resultado da produção de café em sistema convencional das safras 2010/2011 e 2011/2012, a serem comparadas aos resultados do cenário.

Tabela 2 - Sumarização do resultado da produção de café em sistema convencional do Sítio Terra Verde para as safras 2010/2011 e 2011/2012

\begin{tabular}{|c|c|c|}
\hline \multirow{2}{*}{ Variáveis } & \multicolumn{2}{|c|}{ Safras (ano base) } \\
\hline & $2010 / 2011$ & 2011/2012 \\
\hline Lucro $(\mathrm{R} \$)$ & $207.218,59$ & $154.623,62$ \\
\hline Custo de Adubação $(\mathrm{R} \$)^{1}$ & $78.738,80$ & $70.336,85$ \\
\hline Custo de Defensivo $(\mathrm{R} \$)^{2}$ & $24.464,80$ & $22.072,00$ \\
\hline Custo de Colheita $(\mathrm{R} \$)^{3}$ & $110.450,00$ & $105.375,00$ \\
\hline Custo total $(\mathrm{R} \$)^{(1+2+3)}$ & $213.653,60$ & $197.783,85$ \\
\hline Produção (sacas) & $1.099,17$ & 705,69 \\
\hline Receita $(\mathrm{R} \$)$ & $420.872,19$ & $352.407,47$ \\
\hline Custo de beneficiamento e secagem $(R \$)^{4}$ & $36.549,74$ & $29.760,17$ \\
\hline Custo administrativo $(\mathrm{R} \$)^{5}$ & $32.000,00$ & $36.000,00$ \\
\hline Custo Geral $(R \$)^{(1+2+3+4+5)}$ & $282.203,34$ & $263.544,02$ \\
\hline Lucro Geral $(\mathrm{R} \$)$ & $138.668,86$ & $88.863,46$ \\
\hline Talhão 1 (sacas/ha) & 38 & 26,1 \\
\hline Talhão 2 (sacas/ha) & 30,2 & 24 \\
\hline Talhão 3 (sacas/ha) & 33 & 14 \\
\hline Talhão 4 (sacas/ha) & 16,3 & 12,7 \\
\hline
\end{tabular}

Os comportamentos da produção, da receita, do custo e do lucro em sistema convencional, ao longo do período de oito anos, terão valores para as safras 2012/2013, 2014/2015, 2016/2017 e 2018/2019 iguais aos da safra 2010/2011 e para as safras 2013/2014, 2015/2016, 2017/2018 e 2019/2020 iguais aos da safra $2011 / 2012$. 


\section{RESULTADOS}

O resultado do planejamento em conversão está sumarizado no Anexo 1.

A produção total de café beneficiado durante o período encontra-se ilustrada na Figura 2. De acordo com os critérios utilizados sobre a queda de produtividade entre os talhões para o Cenário em Conversão, pode-se observar que as safras de menor produção foram 2015/2016 para os de baixa produção e 2016/2017 para os de alta produção, atingindo uma produção total, respectivamente, de 579,69 sacas e 921,65 sacas, as quais representam uma variação de $-17,9 \%$ e -16,2\%, em relação às mesmas safras se o sistema permanecesse convencional. Na safra de 2015/2016 (4⿳亠口冋 ano de conversão), apenas no talhão 1 não há incidência de fator redutor na produtividade, enquanto na safra 2016/2017 (5 $5^{\text {a }}$ ano de conversão) apenas nos talhões 1 e 2 não incide fator redutor de produtividade.

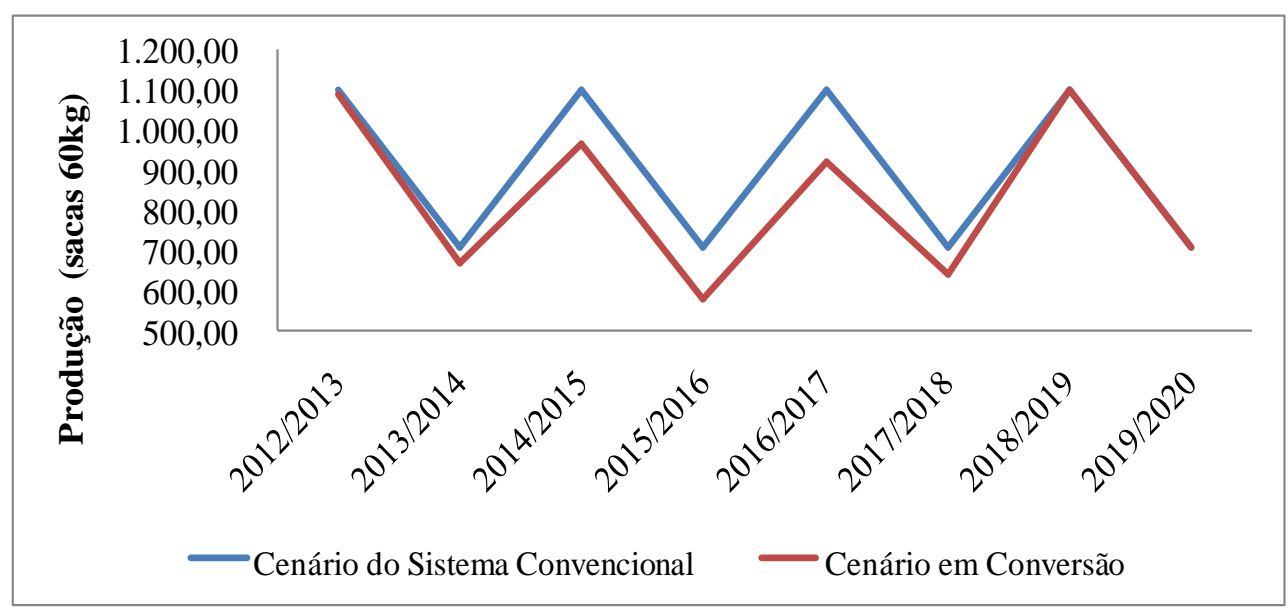

Figura 2 - Oscilação da produção total de café, em sacas, do Cenário em Conversão em comparação à produção em sistema convencional

Nas safras 2018/2019 e 2019/2020, observam-se os mesmos níveis de produção quando em sistema convencional, pois não houve fator redutor na produtividade dos talhões ao final do período, quando em manejo orgânico. É importante deixar claro que, para este estudo de caso, o sistema convencional manteve fixo o nível de produção (safras 2010/2011 e 2011/2012) ao longo do período para possibilitar a comparação entre os cenários. Isso se caracteriza como 
limitação ao resultado, pois o nível de produção, muito provavelmente, irá variar, devido às questões climáticas, problemas fitossanitários etc.

Em se tratando da receita, do custo e do lucro do produtor, serão apresentadas duas ilustrações: uma para as safras 2012/2013, 2014/2015, 2016/2017 e 2018/2019, as quais fazem referência à safra 2010/2011 (alta produção), e outra para as safras 2013/2014, 2015/2016, 2017/2018 e 2019/2020, as quais se referem à safra 2011/2012 (baixa produção).

Observa-se na Figura 3 que na safra 2014/2015 (3ํano de conversão) houve queda na receita e aumento nos custos; consequentemente, observou-se uma redução no lucro para $R \$ 78$ mil, o que implicou uma variação negativa de $43,1 \%$ em relação ao ano base (2010/2011). Isso se deve principalmente à queda de produtividade $(12,3 \%)$ e ao fato de se continuar com o preço do café convencional.

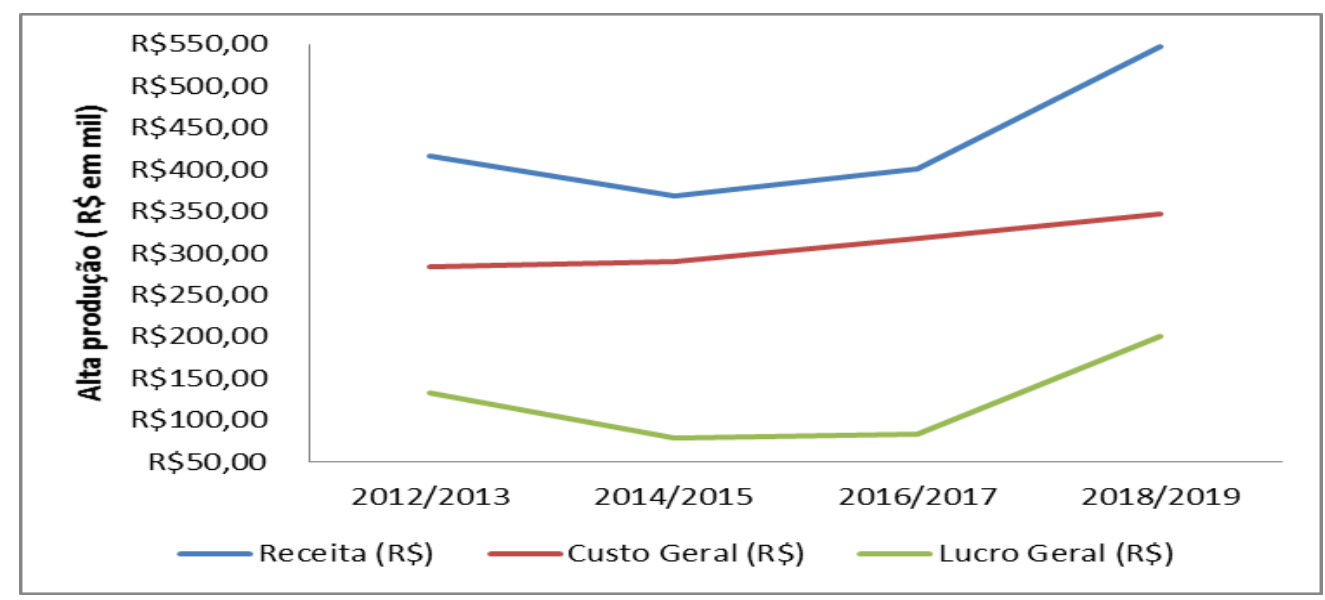

Figura 3 - Evolução da receita, do custo e do lucro, em $\mathrm{R} \$$, do Cenário em Conversão, em anos de alta produção

Quanto aos anos de baixa produção, com base na safra 2011/2012 (Figura 4), o $4^{\circ}$ ano (safra 2015/2016) apresenta uma situação em que o lucro caiu para $\mathrm{R} \$$ $22.153,85$, o que corresponde a uma redução de $75,00 \%$ em relação ao sistema convencional. Isso se deve ao fato de o $4^{\circ}$ ano estar numa condição em que o talhão 1 é orgânico, os talhões 2 e 3 estão em conversão e o talhão 4 está em fase de substituição, resultando na queda acentuada da produção em 17,90\% e num consequente aumento dos custos em $8,24 \%$ e queda de $14,30 \%$ na receita. 


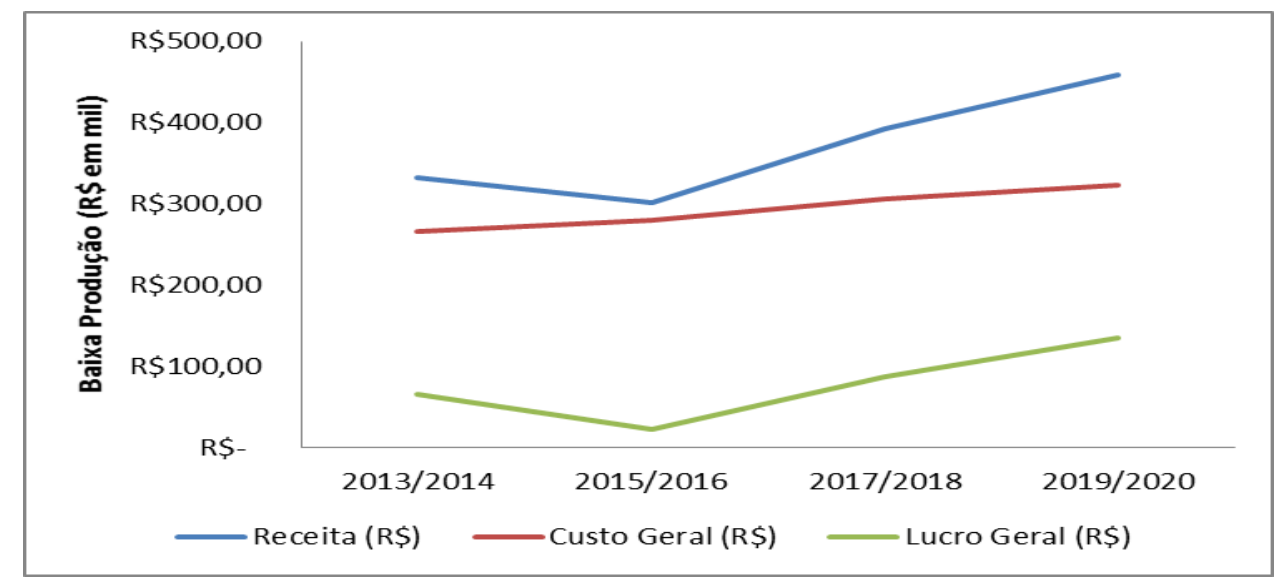

Figura 4 - Evolução da receita, do custo e do lucro, em $(R \$)$, do Cenário em Conversão em anos de baixa produção

Durante o período de conversão para toda a área, observou-se que houve aumentos bastante expressivos ao longo dos anos de alta e de baixa produção. Para o $7^{\circ}$ ano (safra 2018/2019) e $8^{\circ}$ ano (safra 2019/2020) (Figuras 3 e 4), a receita, o custo e o lucro observaram aumento de $30 \%$ em relação à safra 2010/2011 e à safra 2011/2012, respectivamente, em que $100 \%$ da propriedade encontra-se em sistema orgânico.

Diante dessas análises, mesmo considerando o $4^{\circ}$ ano crítico, verifica-se que é viável a produção orgânica aplicada ao café, pois gerou uma situação econômica melhor no final do período do planejamento (lucro geral de $\mathrm{R} \$ 200.834,43$ e $\mathrm{R} \$$ $135.250,54$, respectivamente para as safras $2018 / 2019$ e 2019/2020) em relação ao sistema convencional (lucro geral de $R \$ 138.668,90$ e $R \$ 88.863,46$, respectivamente para os anos base), com mesmo nível de produção e com adicional de $30 \%$ sobre o preço em manejo orgânico, apesar do aumento de 30\% nos custos de produção.

Comparando os cenários com o sistema convencional ao longo do período para as safras de baixa produção (Figura 5), o lucro geral total foi de $R \$ 355.453,83$ contra $R \$ 310.488,89$ do Cenário em Conversão, enquanto para as safras de alta produção o lucro geral total foi de $R \$ 554.675,42$ contra $R \$ 496.608,41$ do Cenário em Conversão. Isso indica que o durante o processo de conversão no período de 
oito anos foi menos vantajoso realizar o processo de conversão, pois proporcionou o menor lucro.

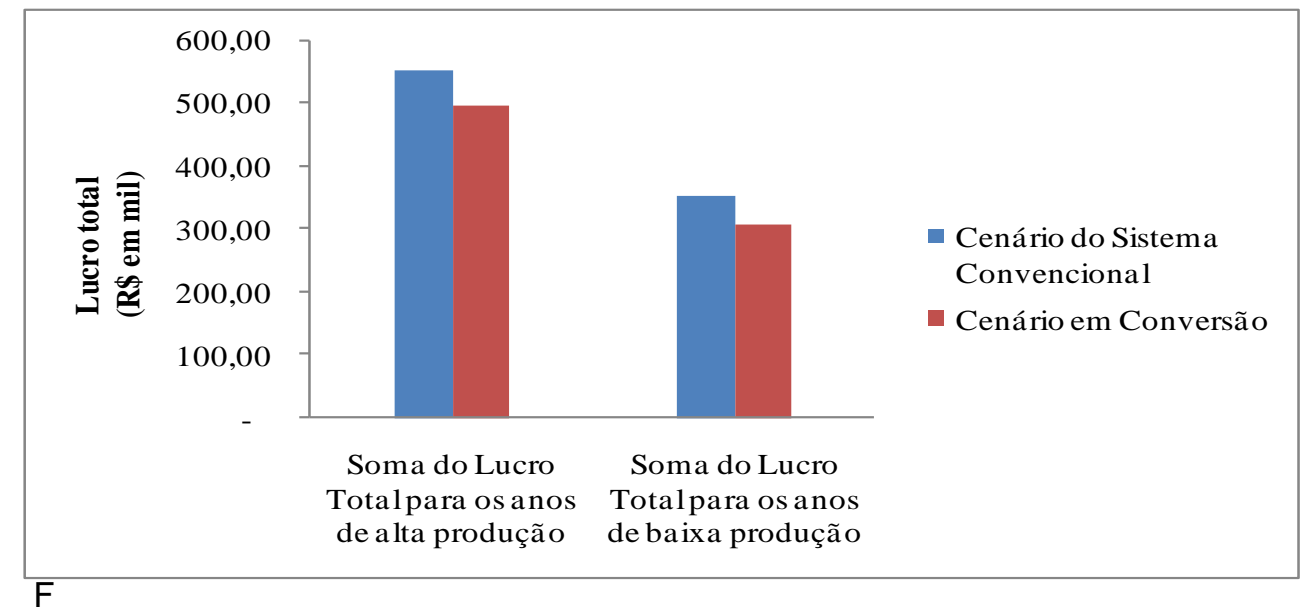

Figura 5 - Comparação do Lucro geral total entre cenários para as safras de alta e baixa produção no período de 2012/2013 a 2019/2020

No entanto, simulando para as próximas safras a partir da safra 2021/2022 até a safra 2027/2028, Figura 6, para os anos de baixa produção (correspondendo às safras 2021/2022, 2023/2024, 2025/2026 e 2027/2028), mantendo-se fixo o nível de produção de café orgânico (não está em conversão), o lucro geral total será de $\mathrm{R} \$ 541.002,18$, enquanto para os anos de alta produção (correspondendo às $2020 / 2021,2022 / 2023,2024 / 2025$ e 2026/2027) o lucro geral total será de $R \$$ 803.337,73, indicando a vantagem de se produzir em sistema orgânico em relação ao convencional de maneira sustentável.

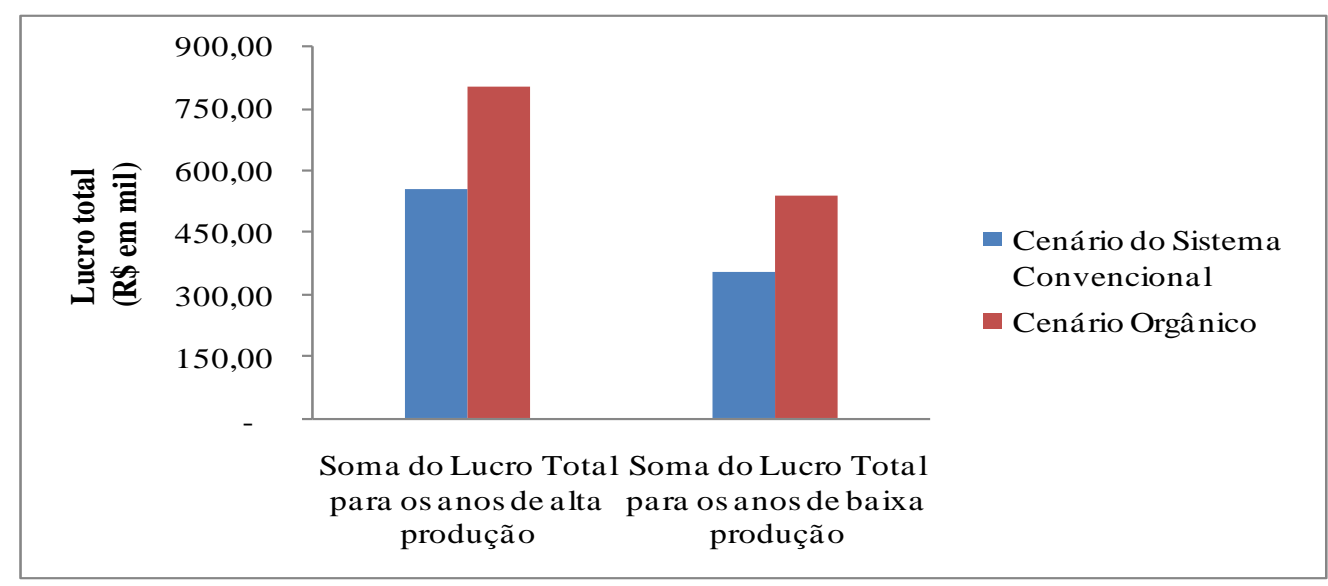

Figura 6- Comparação do Lucro geral total entre cenários para as safras de alta e baixa produção no período de 2021/2022 a 2027/2028 
Portanto, diante da variação do lucro geral em relação ao cenário em conversão, é possível afirmar que seja viável economicamente a produção orgânica aplicada ao café, mediante o aumento de $30 \%$ dos custos, por não ocorrer fator redutor de produtividade em manejo em orgânico e pela bonificação de $30 \%$ sobre o preço da saca em função da certificação a ser obtida.

Siqueira e Souza (2012) observaram que a renda líquida operacional unitária obtida com o café orgânico e o lucro unitário foram, respectivamente, 5,4 vezes maior e 447,6 vezes maior que o convencional. A margem bruta operacional do café orgânico foi maior em 4,5 vezes que a do café convencional, enquanto a margem total foi maior em 353,4 vezes. Já os índices benefício/custo operacional e total do café orgânico foram $30 \%$ e $28 \%$ superiores, respectivamente. Percebe-se que a agricultura orgânica é uma atividade que eleva a rentabilidade do produtor.

\section{CONCLUSÃO}

O planejamento permitiu a possibilidade de simular o processo de conversão do café convencional para orgânico por meio da variável produção, produtividade, receita, custo e lucro do cafeicultor.

Conclui-se que a adoção da técnica orgânica proporcionou proventos ao cafeicultor (proprietário do Sítio Terra Verde), com lucros superiores aos do sistema convencional no final do período de conversão. O sistema de produção orgânica se mostrou economicamente viável se o produtor receber um incremento de $30 \%$ sobre o preço da saca de café e se a produtividade retornar aos mesmos níveis do sistema convencional. Os resultados ainda revelaram que o quarto ano é um ano crítico, pois deteve menor nível de lucro do planejamento, em função da maior incidência do fator redutor de produção e do aumento de custo em toda a área.

Também é possível inferir, mediante este estudo, que a viabilidade econômica em sistema orgânico de produção é extremamente dependente do diferencial de preço em relação ao sistema convencional.

Por meio do aumento induzido de custos de produção de até $30 \%$, o cafeicultor só poderá ter vantagem, ao produzir organicamente, se houver o 
incremento de no mínimo $30 \%$ sobre o preço de venda por saca em relação ao convencional.

O sistema orgânico de produção para o café pode ser uma alternativa tecnológica para minimizar o impacto ambiental, com lucros superiores ao sistema não orgânico.

Recomenda-se para trabalhos posteriores a realização de estudos sobre lavouras que estão em processo de conversão, para analisar não apenas a comparação entre o convencional e o orgânico, mas também acompanhar e destacar as dificuldades enfrentadas, principalmente sobre a aquisição de insumos, a certificação e o preço diferenciado, pelos agricultores para tentar solucioná-los.

\section{REFERÊNCIAS}

ALENCAR, V. C.; MOTA, J. C.; SANTOS, V.; VIEIRA, A. S.; CURI, W. F. (2009). Multiobjective comparative analysis between an organic production system and a conventional production system. In: CIGR-International Conference of Agricultural Engineering, Foz do Iguaçu, v. 1, p. 1-18.

ALTIERE, M. (2011). Agroecologia: a dinâmica produtiva da agricultura sustentável. 5. ed. Porto Alegre: UFRGS, 2004. 120 p. Disponível em: $<$ www.agroeco.org/socla/archivospdf/Agroecologia_-short-port.pdf $>$. Acesso em: 10 mai.

ASSIS, R. L.; ROMEIRO, A. R. (2004). Análise do processo de conversão de sistemas de produção de café convencional para orgânico: um estudo de caso. Cadernos de Ciência \& Tecnologia, Brasília, v. 21, n. 1. 143-168.

BARBOSA, W. F.; SOUSA, E. P. (2012). Agricultura orgânica no Brasil: características e desafios. Revista Economia \& Tecnologia, v. 8, n. 4, p. 67-74.

BRADLEY, Teresa. (2011). Matemática aplicada à administração. Rio de Janeiro: Elsevier.

BRASIL. Instrução Normativa $n^{\circ}$ 64, de 18 de dez. (2008). Aprova o Regulamento Técnico para os Sistemas Orgânicos de Produção Animal e Vegetal. Diário Oficial, Brasília, 19 dez. 2008. Seção 1, p. 21.

. Lei n. 10.831, de 23 de dezembro de 2003. Dispõe sobre a Agricultura Orgânica e dá outras providências. Diário Oficial, Brasília, 24 dez. 2003a. Seção 1, p. 8. 
- Ministério da Agricultura, Pecuária e Abastecimento. Disponível em: <http://www.agricultura.gov.br/>. Acesso em: 20/jul/2014.

BUAINAIN, A. M.; SOUZA FILHO, H. M.; SABBATO, A.; SOUZA, A. C.; GUANZIROLI, C.; SILVEIRA, J. M.; BATALHA, M. O.; SALLES FILHO, S. L. M. (2007). Agricultura familiar e inovação tecnológica no Brasil: características, desafios e obstáculos. Campinas: Editora da Unicamp, v. 1. 238 p.

FIBL - Research Institute of Organic Agriculture; IFOAM - Federação Internacional de Movimentos de Agricultura Orgânica. Organic agricultural land by conversion status by country and region 2005-2011. Disponível em:<http://www.organic-world.net >. Acesso em: 10/jun/2013.

INSTITUTO BRASILEIRO DE GEOGRAFIA E ESTATÍSTICA. Censo agropecuário 2006. Rio de Janeiro, 2006. Disponível na Internet: <http://www.sidra.ibge.gov.br/>. Acesso em: 05/mar/2013.

JAFFE, A.B.; NEWELL, R.G.; STAVINS, R. (2002). Environmentalpolicy and technological change. Environmental and Resource Economics, Netherlands, n. 22,p. 41-69. 2002.

MAIORANO, J. A. (2000). Estratégias para conversão em agricultura orgânica. In: MURAOKA, T. Adubação verde para agricultura orgânica: dia de campo. Piracicaba: Degaspari, $172 \mathrm{p}$.

MARTINS, R. V.; BRAUN, M. B. S.; LIMA, J. F.; STADUTO, J. A. R. (2006). Agricultura Orgânica como fonte de emprego e renda: um estudo de caso da produção vitinícola. In: CONGRESSO DA SOCIEDADE BRASILEIRA DE ECONOMIA E SOCIOLOGIA RURAL, 44. Fortaleza. Anais...Fortaleza: SOBER, v. 1, p. 1-13.

MENDES, J.T.G. (1989). Economia agrícola: princípios básicos e aplicações. Curitiba: Scientia et Labor, $399 \mathrm{p}$.

MESQUITA, T.C. Impacto da mudança tecnológica na produção agrícola: aproximação de uma análise dinâmica. Cadernos de Ciência \& Tecnologia, Brasília, v. 13, n. 2, p. 159-173, 1996.

. Estudos de economia agrícola. Sobral: Edição UVA, 1998. 168 p.

MOTTA, I.S.; CUNHA, F.A.D.; SENA, J.O.A.; CLEMENTE, E.; CALDAS, R.G.; LORENZETTI, E.R. (2008). Análise econômica da produção do maracujazeiro amarelo em sistemas orgânico e convencional. Ciência Agrotecnologia, Lavras, v. 32, n. 6, p. 1927-1934, dez.

NUTLEY, S.; DAVIES, H.; WALTER, I. (2011). Conceptual synthesis 1: learning from the diffusion of innovations, research unit for research utilization. University of St. Andrews, 2002. Disponível em: <http://www.ruru.ac.uk>. Acesso em: 30 set. 
PAIVA, R.M. (1975). Modernização e dualismo tecnológico na agricultura. Pesquisa e Planejamento Econômico, Rio de Janeiro, v. 5, n. 1, p. 117-161, jun.

PANZENHAGEN, N. V.; KOLLER, O. C.; VAQUIL, P. D.; SOUZAS, P. V. D.; SÓGLIO, F. K. D. (2008). Aspectos técnico-ambientais da produção orgânica na região citrícola do Vale do Rio Caí, Rio Grande do Sul. Ciência Rural, Santa Maria, v. 38, p. 90-95.

PENSA- Centro de Conhecimento em Agronegócios. (2009). Perfil do produtor de café do Brasil: relatório de pesquisa. São Paulo. Disponível em: <http://www.pensa.org.br/ANEXOs/biblioteca/239200814543_relatorio_illy.pdf> Acesso em: 27/abr/2011.

PENTEADO, S. R. (2009). Manual prático de agricultura orgânica: fundamentos e técnicas. Campinas: Via Orgânica, 213 p.

RICCI, M. S. F.; ARAÚJO, M. C. F.; CASTRO, C. M. (2002). Cultivo orgânico do café: recomendações técnicas. Brasília: Embrapa Informação Tecnológica. 101 p.

SACHUCK, M. I.; TAKAHASHI, L. Y.; AUGUSTO, C. A. (2008). Impactos da inovação tecnológica na competitividade e nas relações de trabalho. Caderno de Administração, Maringá, v. 16, n. 2, p. 57-66, jul./dez.

SAMPAIO, D. B.; ARAÚJO, A. S. F.; SANTOS, V. B. (2008). Avaliação de indicadores biológicos de qualidade do solo sob sistemas de cultivo convencional e orgânico de frutas. Ciência Agrotecnologia, Lavras, v. 32, n. 2, p. 353-359, abr.

SAES, M. S. M.; SOUZA, M. C. M.; OTANI, M. N. (2001). Actions to promove sustainable development: the case of Baturite shaded coffe, state of Ceará, Brazil. FAO-Food and Agriculture Organization of the United Nations. São Paulo, 36 p.

SIQUEIRA, H. M.; SOUZA, P. M. (2012). O sistema orgânico de produção e a cafeicultura familiar do Caparaó-ES: alternativa para a sustentabilidade socioeconômica? Custose @gronegócio Online,v. 8, p. 57-83.

SIQUEIRA, H. M.; SOUZA, P. M.; PONCIANO, N. J. (2011). Café convencional versus café orgânico: perspectivas de sustentabilidade socioeconômica dos agricultores familiares do Espírito Santo. Revista Ceres, Viçosa, v. 58, p. 155-160, mar./abr.

SILVA JUNIOR, P. B.; SOUZA, P.; SOUZA, R. M.; LUNKES, R. J. (2014). Estudo Comparativo entre Agricultura Orgânica e Convencional no Cultivo de Morango em Rancho Queimado/SC. Revista Ibero-Americana de Ciências Ambientais, v. 5, p. 115-125.

TURCO, P. H. N.; OLIVEIRA, M. D. M.; BUENO, O. C. (2010). Custo de implantação da cultura do café para sistemas de produção convencional e orgânicos em diferentes regiões. In: CONGRESSO DA SOCIEDADE BRASILEIRA DE ECONOMIA 
E SOCIOLOGIA RURAL, 48., 2010, Campo Grande. Tecnologia, desenvolvimento e integração social. Anais...Campo Grande: SOBER, 1 CD-ROM.

TURRA, C.; GHISI, F. A. (2004). Laranja orgânica no Brasil: produção, mercado e tendências. In: CONGRESSO DA SOCIEDADE BRASILEIRA DE ECONOMIA E SOCIOLOGIA RURAL, 42., 2004, Cuiabá. Anais...Cuiabá: SOBER, 1 CD-ROM.

Data de Submissão: 13/06/2015

Data de Aceite: 18/03/2016 


\section{Anexo 1 - Resultados do planejamento da conversão}

\begin{tabular}{lrrrrrrrr}
\hline Variáveis & $2012 / 2013$ & $2013 / 2014$ & $2014 / 2015$ & $2015 / 2016$ & $2016 / 2017$ & $2017 / 2018$ & $2018 / 2019$ & $2019 / 2020$ \\
\hline Lucro (R\$) & $201.742,50$ & $131.658,40$ & $147.515,70$ & $87.914,01$ & $152.165,00$ & $152.946,40$ & $269.384,20$ & $201.010,70$ \\
Adubação (R\$) & $79.386,97$ & $73.204,54$ & $86.778,80$ & $83.949,22$ & $99.356,78$ & $91.437,91$ & $102.360,40$ & $91.437,91$ \\
Defensivo (R\$) & $24.758,26$ & $22.764,84$ & $26.848,52$ & $26.160,68$ & $30.966,88$ & $28.693,60$ & $31.804,24$ & $28.693,60$ \\
Colheita (R\$) & $110.328,40$ & $104.812,50$ & $107.785,70$ & $103.975,70$ & $118.030,90$ & $119.981,60$ & $143.585,00$ & $136.987,50$ \\
Custo (R\$) & $214.473,60$ & $200.781,90$ & $221.413,00$ & $214.085,50$ & $248.354,60$ & $240.113,10$ & $277.749,70$ & $257.119,00$ \\
Produção (sacas) & $1.087,01$ & 665,71 & 963,51 & 579,69 & 921,65 & 640,54 & $1.099,17$ & 705,69 \\
Receita (R\$) & $416.216,10$ & $332.440,30$ & $368.928,70$ & $301.999,60$ & $400.519,50$ & $393.059,50$ & $547.133,90$ & $458.129,70$ \\
Custo de beneficiamento e secagem (R\$) & $36.549,74$ & $29.760,17$ & $36.549,74$ & $29.760,17$ & $36.549,74$ & $29.760,17$ & $36.549,74$ & $29.760,17$ \\
Custo Administrativo (R\$) & $32.000,00$ & $36.000,00$ & $32.000,00$ & $36.000,00$ & $32.000,00$ & $36.000,00$ & $32.000,00$ & $36.000,00$ \\
Custo Geral (R\$) & $283.023,40$ & $266.542,00$ & $289.962,80$ & $279.845,70$ & $316.904,30$ & $305.873,20$ & $346.299,40$ & $322.879,20$ \\
Lucro Geral (R\$) & $133.192,80$ & $65.898,22$ & $78.965,99$ & $22.153,85$ & $83.615,23$ & $87.186,28$ & $200.834,40$ & $135.250,50$ \\
Talhão 1 (sacas/ha) & 34,2 & 20,88 & 26,6 & 26,1 & 38 & 26,1 & 38 & 26,1 \\
Talhão 2 (sacas/ha) & 30,2 & 21,6 & 24,16 & 16,8 & 30,2 & 24 & 30,2 & 24 \\
Talhão 3 (sacas/ha) & 33 & 14 & 29,7 & 11,2 & 23,1 & 14 & 33 & 14 \\
Talhão 4 (sacas/ha) & 16,3 & 12,7 & 16,3 & 11,43 & 13,04 & 8,89 & 16,3 & 12,7 \\
\hline
\end{tabular}

